\title{
VIEWPOINT
}

\section{Protocols in the management of critical illness}

Steven Y Chang ${ }^{1 *}$, Jon Sevransky ${ }^{2}$ and Greg S Martin ${ }^{3}$

\begin{abstract}
Care of the critically ill patient is becoming increasingly complex. Protocols, which standardize care of patients with similar diseases, represent a potential solution to managing multiple simultaneous problems in critically ill patients. In this article, we examine the advantages and disadvantages to care protocolization, and posit that careful and thoughtful implementation of protocols is likely to benefit patients. We also discuss the potential for unintended consequences, and even harm, with protocolization in critically ill patients using the Critical Illness Outcomes Study as a model to examine the effects of protocolization in large populations of intensive care patients.
\end{abstract}

\section{Introduction}

Care of the critically ill patient is often punctuated with physiologic changes that require immediate attention. Given the frequency of emergent interventions, clinicians may be distracted from important, less urgent tasks that are still essential for optimal patient care. For this and other reasons, the utilization of protocols in the ICU can potentially improve the care of the critically ill patient. Because of the complexities of caring for the critically ill patient, the use of protocols in the ICU has become increasingly common. We will review the definition of a protocol, discuss their advantages, and highlight some of their limitations and potential for harm with their use

There are multiple definitions for protocols. We prefer that of Fessler and Brower [1], who define protocols as 'sets of explicit, algorithmic rules, which direct clinical management or research'. Similarly, Alan Morris [2] defined protocols as 'precise and detailed plans for the study of a medical or biomedical problem and/or for a regimen of therapy', which should be differentiated from

*Correspondence: changsy@umdnj.edu

'Division of Pulmonary and Critical Care Medicine, University of Medicine and Dentistry of New Jersey - New Jersey Medical School, 150 Bergen St, UH-I354, Newark, NJ 07103, USA

Full list of author information is available at the end of the article guidelines, defined as 'a systematic statement of policy rules or principles', in which explicit directions for making choices or decisions do not exist. Checklists, by contrast, are lists of things to be completed or checked. A protocol may be implemented by the use of a checklist, and can be used to facilitate specific treatment guidelines. When protocols are properly used, clinicians more frequently treat similar patients in a similar fashion. Protocols have the potential to minimize medical errors, decrease the likelihood of injury, increase patient safety and improve patient outcomes.

\section{How can protocols improve patient care?}

Protocols can minimize inconsistencies in the care of similar patients by the myriad healthcare providers in an ICU. Variability in clinician behavior is a product of varied educational backgrounds and experience [3]. In fact, a single physician might even respond to similar patients and situations, at different times, in different fashion [4]. Given these issues, protocols can prove useful when applied in a judicious and thoughtful fashion, as their intent is to reduce unnecessary variations in physician response to patients with defined disease processes [1,5] (Table 1).

Protocols can effect knowledge translation [1]. Outcomes of clinical research do not always readily nor appropriately make their way into clinical practice, and therapies can be both underused or applied to unsuitable candidates [6]. Protocols are one method to more quickly adapt new information to bedside care. A recent example of such delay in knowledge translation involves the ventilator management of patients with acute lung injury (ALI) and acute respiratory distress syndrome (ARDS). Even though the original ARMA trial, comparing tidal volumes of $6 \mathrm{~mL} / \mathrm{kg}$ versus $12 \mathrm{~mL} / \mathrm{kg}$ predicted body weight in ALI subjects, was published over a decade ago, only a fraction of patients are being treated with appropriate tidal volumes, even at participating ARDSnet centers [7-9]. The use of a lung protective mechanical ventilation protocol was the factor most likely to be associated with use of appropriate tidal volumes in ALI patients [10]. Explicit instructions for identification of appropriate patients and for setting tidal volumes and positive end-expiratory pressure (PEEP) based on predicted body weight and oxygenation targets has the 
Table 1. Advantages and disadvantages of protocols

\begin{tabular}{ll}
\hline Advantages & Disadvantages \\
\hline Reducing unnecessary variability in care & Use in inappropriate patient \\
Quick adoption of new information to the bedside & Loss of individualization of care \\
Streamlining of care & Potential to be obsolete if not kept current \\
Educational aids & May be designed around low quality evidence \\
Improved communication & May be oversimplified \\
Cost containment & \\
Decrease errors and improve patient safety & \\
\hline
\end{tabular}

potential to prevent errors in which healthcare providers order inappropriate ventilator settings. In so doing, care is improved, and evidence is translated and applied at the bedside.

Likewise, protocols can streamline the care of critically ill patients [1]. It was demonstrated that non-physician providers could easily identify patient readiness for liberation from mechanical ventilator support [11]; 95\% of daily assessments were correctly interpreted by respiratory therapists in the absence of physician guidance, and with time, the therapists grew increasingly comfortable with asking intensivists for spontaneous breathing trial orders. This improved use of the multidisciplinary team should allow timely performance of desired therapies while freeing up the physician to focus on other urgent issues.

Additionally, protocols may facilitate the teaching of appropriate clinical management for select diseases [1]. They can become tools used for discussion and education, and those protocols that are multidisciplinary can assist with the teaching of teamwork. Prasad et al. [12], in a retrospective cohort equivalence study, demonstrated that fellows who trained in a highly protocolized environment (defined as critical care units that had two or more protocols for at least 3 years prior to study) performed as well as those who trained in critical care units that were not highly protocolized (no or one protocol), on the subset of questions on the American Board of Internal Medicine Critical Care Boards regarding mechanical ventilation.

Importantly, protocols can improve patient safety by decreasing errors of both omission (a failure to perform beneficial actions) and commission (implementation of injurious actions despite appropriate intentions). That is, protocols can increase the likelihood that needed therapies are not overlooked, and that they are implemented as intended. Patient safety could potentially be enhanced by protocolizing other processes, such as provider-to-provider communication and hand-offs ('the transfer of patient care from one health care provider to another' [13]), especially in an era in which resident physicians have limits on their work hours, outpatient doctors are relinquishing inpatient care to hospitalists, and many ICUs are adopting a shift work schedule in order to maximize coverage by attending physicians. Communication becomes vital to ensure that no details are missed, and a protocol for hand-offs could help assure this. In a recent review of the literature looking at transition of care from one physician to another, the most cited solution to poor quality hand-offs was standardization, although this and other proposed solutions still require careful study [13].

Protocols could potentially help contain costs by reducing inconsistencies in practice since variability in clinical practice results not only in variable outcomes, but also in variable costs. In a prospective, observational study of nine intensivists at a single university ICU, physicians were the third biggest driver of cost variation behind severity of illness and type of critical illness [14]. By formalizing care for complex disease processes, unnecessary tests might be avoided, complications from incorrect and unneeded therapies could be minimized, and resource utilization might be improved. Kress et al. [15], by protocolizing sedation interruption, showed a reduction in the length of mechanical ventilatory support from 7.3 to 4.9 days, and a reduction in ICU length of stay (LOS) from 9.9 days to 6.4 days. Ely et al. [16] demonstrated a reduction in ICU costs from a median of $\$ 20,890$ (interquartile range $\$ 11,501$ to $\$ 37,570$ ) to $\$ 15,740$ (interquartile range $\$ 7,873$ to $\$ 33,035$ ) per patient using a respiratory therapy driven weaning protocol.

Weaning protocols and their effects on multiple outcomes were recently examined in a Cochrane review, in assessing how patients might benefit from an algorithmic approach to care [17]. The primary outcome was duration of mechanical ventilation, while the secondary outcomes included ICU and hospital mortality, adverse events (re-intubation, tracheostomy, prolonged ventilation), duration of weaning, ICU and hospital LOS, and cost. No pre-specified outcomes were adversely affected while duration of mechanical ventilation was reduced by $25 \%$ (95\% confidence interval of 9 to $39 \%, P=0.006$ in 10 studies), duration of weaning was reduced by $78 \%$ (31 to 
$93 \%, P=0.009$ in 6 studies), and ICU LOS was reduced by $10 \%$ ( 2 to $19 \%, P=0.02$ in 8 studies). In addition to weaning, other protocols that have been developed are those involving daily awakening, lung protective ventilation, and severe sepsis/septic shock, anemia, ischemic stroke, and hypothermia after cardiac arrest [7,11,15,16,18-24] (Table 2).

Outcomes of selected interventions that might be considered for protocolization are shown in Table 3 .

\section{Caveats to protocolized care}

In addition to their advantages, we list some potential downsides to implementing protocols in the ICU in Table 1. Protocols might be used in patients who would not benefit from their use as clinicians less familiar with their elements or suspected illness may incorrectly use them or inappropriately adapt their use. Perhaps automated, non-physician ordered protocols may be viewed as a solution, by some institutions, to ensuring the use of protocols. This risks, however, the implementation in inappropriate patients since many protocols require careful consideration with regards to whether they should be implemented. Because protocols are generally based on evidence in the literature, they are truly only applicable to the patient populations in which they were originally studied, so care must be taken to avoid applying protocols to inappropriate patients. For instance, a septic shock protocol might not be appropriate in cardiogenic or hemorrhagic shock patients even though all these patients are grossly similar. Likewise, a daily awakening and spontaneous breathing trial protocol may work less well, or even be inappropriate, for a neurosurgical or cardiac patient compared to a medically critically ill patient.

Medicine evolves, as shown by changes in the data about glycemic control, steroids and activated protein $\mathrm{C}$ in the past decade [21,25-31]. For instance, tight glucose control protocols were soon developed at many medical centers after the initial publication showing benefit of strict glycemic control in surgical critical care patients [31]. Follow-up studies, however, could not confirm the benefit of the initial study, and in fact showed harm $[28,29]$. Protocols need to be 'living documents'. They should be developed in rational fashion using best evidence, avoiding the incorporation of low quality recommendations and guidelines, and kept current, all by careful review of the literature and data [32]. Protocols are only as good as the evidence from which they are derived.

If protocols are complex and difficult to follow, clinicians will resist them, or perhaps even only incorporate selective portions [33]. For example, even easily followed protocols for PEEP might not always be used, and almost certainly, complex PEEP protocols are rarely

\section{Table 2. Interventions/processes amenable to} protocolization

Ventilator weaning

Acute lung injury/lung protective ventilation

Sepsis

Rapid antibiotic administration

Daily interruption of sedation

Other sedation

Catheter placement

Venous thromboembolism prophylaxis

Early mobility

Stress ulcer prevention

Nutrition

Transfusion restriction

Massive transfusion

Hypothermia after cardiac arrest

Ventilator-associated pneumonia prevention

Delirium assessment

Delirium treatment

Palliative care/end of life

Electrolyte replacement

Acute coronary syndrome

Acute brain injury

Stroke

Intracerebral hemorrhage

Glucose control

Critical care code/Advanced Cardiac Life Support (ACLS)

Oral hygiene

followed outside of the research setting [7,34]. Protocols may be inadvertently simplified to the point that they no longer apply to many patient populations or that they no longer account for complex physiology.

As protocols are inherently rigid, there is concern that individualized care is ignored. In the absence of highly sophisticated artificial intelligence systems, they will never be as good as the best, well-trained, seasoned clinicians who can respond quickly to changing conditions. There are no protocols that can effectively deal with all clinical scenarios, and patients with rare diseases or those with unusual presentations of common diseases may not be well served by a protocol that was not designed to fit their specific situation. For example, differences in drug metabolism across patients may lead to differences in response to particular medication protocols. Obesity, for instance, can affect drug distribution and metabolism in a difficult to predict fashion because of increased adiposity, and changes in physiology (increased cardiac output and blood volume, altered liver 
Table 3. Outcomes of selected interventions

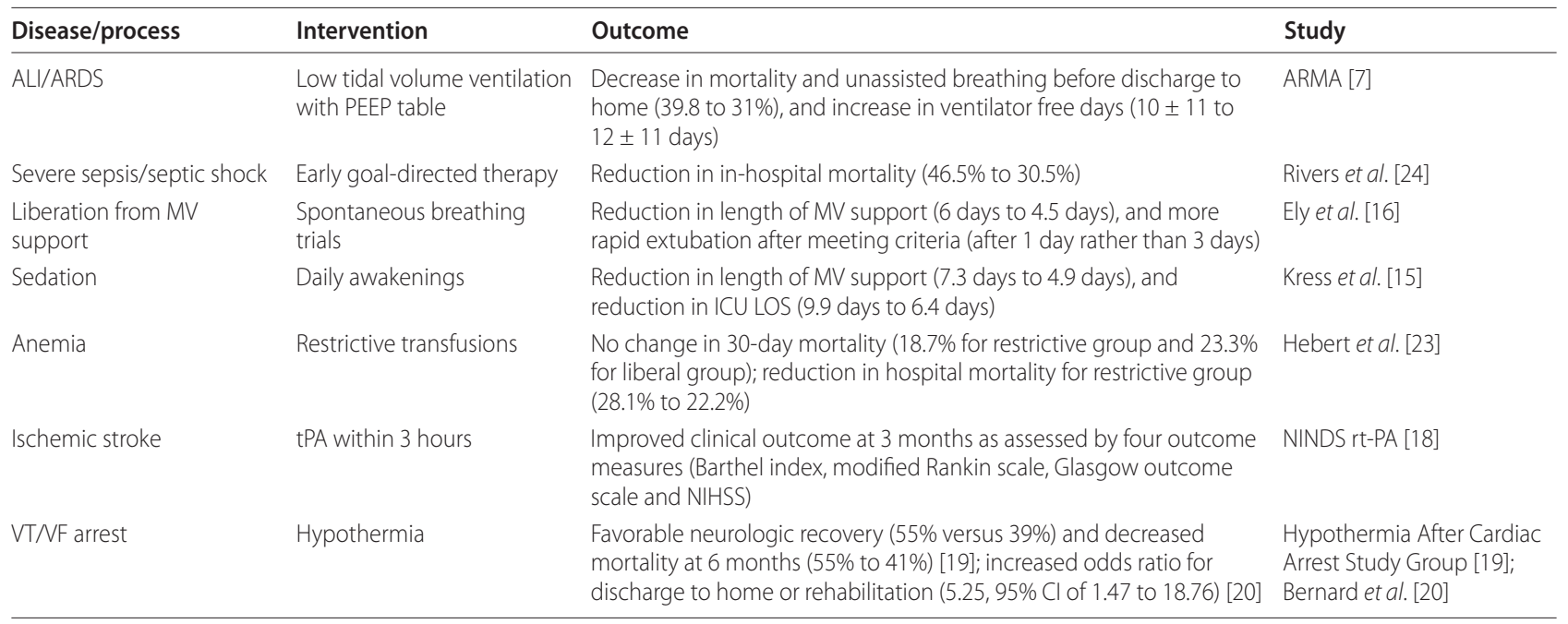

ALI, acute lung injury; ARDS, acute respiratory distress syndrome; $\mathrm{Cl}$, confidence interval; LOS, length of stay; MV, mechanical ventilation; NINDS rt-PA, National Institute of Neurological Disorders and Stroke rt-PA Stroke Study Group; PEEP, positive end-expiratory pressure; tPA, tissue plasminogen activator; VF, ventricular fibrillation; VT, ventricular tachycardia.

and renal metabolism, and changes in serum protein levels) [35]. Likewise, drug metabolism in the elderly can be unpredictable given age-related changes in organ function, multiple chronic illnesses and polypharmacy [36]. Additionally, many critically ill states, such as severe sepsis and septic shock, result in abnormal regional blood flow.

To summarize, the successful protocolization of medicine requires rapid and correct identification of disease processes, the need for thoughtful consideration of the inclusion and exclusion criteria for application of protocols to appropriate patients, and algorithms derived from good quality evidence.

\section{Future directions}

Computers and artificial intelligence systems will likely play an increasing role in clinical medicine. Sophisticated, commercially available computer-driven protocols for weaning and liberating patients from mechanical ventilator support already exist, although studies demonstrate mixed results with regards to their performance, possibly related to their application in inappropriate patient populations $[37,38]$. Certainly, there seems to be potential for these and similar systems to improve the care of carefully selected patient populations. Likewise, Computer Physician Order Entry (CPOE) systems may facilitate the use of protocols via prompts, and could allow for flexibility as clinicians could select or de-select appropriate therapies within the bounds of a protocol. Given enough information, it might be possible to design an intelligent system in order to both identify patients to whom protocols would be applicable and prevent use in patients with exclusion criteria.

\section{Understanding the effects of ICU protocolization}

Many institutions, in an attempt to improve care, have adapted protocols without strong supporting evidence. More research about specific protocols, and, more generally, about the role of protocols in patient care needs to be performed. We need to determine whether patient safety, outcomes and costs are reliably improved by protocols. As an initial step, the Critical Illness Outcomes Study (CIOS), organized through the US Critical Illness and Injuries Trials (USCIIT) Group, is being conducted to examine organizational and structural factors in adult ICUs, and to determine their association with patient-related treatments and outcomes [39]. CIOS will enhance our understanding of the relationship between ICU protocols, both availability and utilization, and clinical outcomes.

Weiss et al. [40] recently demonstrated that verbal prompts to use a checklist resulted in significantly decreased mortality and significantly shorter LOS when compared to the control in which checklists were used without prompts. While checklists are not as explicit as protocols (and although they can be used to improve protocol initiation), their purpose, similar to protocols, is to improve patient care processes.

The next logical step, if protocols can be shown to be reliably beneficial, is their widespread implementation into the community. Fessler and Brower [1] and Morris et al. [41] elegantly outline necessary steps in generating explicit and valid protocols, and in clinician acceptance of protocols.

\section{Conclusion}

Because of the complexities of the critically ill patient, the ICU is a logical place in which to implement 
protocols. We believe that most patients are best served in ICUs that emphasize multidisciplinary, team-based care and conscientious application of protocols. The advantages of protocols can be maximized by their careful development and implementation, by the proper identification of appropriate patient populations, and through incorporation of educational components. We are not aware of reliable data showing worsening of outcomes with protocols, but we believe that more research is still necessary to fully understand their role in ICU patient care.

\section{Abbreviations}

ALI, acute lung injury; ARDS, acute respiratory distress syndrome; CIOS, Critical Illness Outcomes Study; LOS, length of stay; PEEP, positive end-expiratory pressure.

\section{Competing interests}

The authors declare that they have no competing interests.

\section{Author details}

'Division of Pulmonary and Critical Care Medicine, University of Medicine and Dentistry of New Jersey - New Jersey Medical School, 150 Bergen St, UH-I354, Newark, NJ 07103, USA. 2Division of Pulmonary, Allergy and Critical Care, Emory University School of Medicine, 1365 Clifton Road, Suite A4305, Atlanta, GA 30322, USA. ${ }^{3}$ Division of Pulmonary, Allergy and Critical Care, Emory University School of Medicine, 49 Jesse Hill Jr Drive SE, Atlanta, GA 30303, USA.

Published: 16 March 2012

\section{References}

1. Fessler HE, Brower RG: Protocols for lung protective ventilation. Crit Care Med 2005, 33(3 Suppl):S223-227.

2. Morris AH: Treatment algorithms and protocolized care. Curr Opin Crit Care 2003, 9:236-240

3. Billington EO, Zygun DA, Stelfox HT, Peets AD: Intensivists' base specialty of training is associated with variations in mortality and practice patterns. Crit Care 2009, 13:R209.

4. Tierney J: Do you suffer from decision fatigue? New York Times Magazine 2011 [http://www.nytimes.com/2011/08/21/magazine/do-you-suffer-from-decisionfatigue.html?sq=Decision\%20Fatigue\&st=cse\&scp=1\&pagewanted=all]

5. Morris AH: Rational use of computerized protocols in the intensive care unit. Crit Care 2001, 5:249-254.

6. Lenfant C: Shattuck lecture - clinical research to clinical practice - lost in translation? N Engl J Med 2003, 349:868-874.

7. Ventilation with lower tidal volumes as compared with traditional tidal volumes for acute lung injury and the acute respiratory distress syndrome. The Acute Respiratory Distress Syndrome Network. N Engl J Med 2000, 342:1301-1308.

8. Irish Critical Care Trials Group: Acute lung injury and the acute respiratory distress syndrome in Ireland: a prospective audit of epidemiology and management. Crit Care 2008, 12:R30.

9. Checkley W, Brower R, Korpak A, Thompson BT: Effects of a clinical trial on mechanical ventilation practices in patients with acute lung injury. $\mathrm{Am} J$ Respir Crit Care Med 2008, 177:1215-1222.

10. Umoh NJ, Fan E, Mendez-Tellez PA, Sevransky JE, Dennison CR, Shanholtz C, Pronovost PJ, Needham DM: Patient and intensive care unit organizational factors associated with low tidal volume ventilation in acute lung injury. Crit Care Med 2008, 36:1463-1468.

11. Ely EW, Bennett PA, Bowton DL, Murphy SM, Florance AM, Haponik EF: Large scale implementation of a respiratory therapist-driven protocol for ventilator weaning. Am J Respir Crit Care Med 1999, 159:439-446.

12. Prasad M, Holmboe ES, Lipner RS, Hess BJ, Christie JD, Bellamy SL, Rubenfeld GD, Kahn JM: Clinical protocols and trainee knowledge about mechanical ventilation. JAMA 2011, 306:935-941.

13. Riesenberg LA, Leitzsch J, Massucci JL, Jaeger J, Rosenfeld JC, Patow C, Padmore JS, Karpovich KP: Residents' and attending physicians' handoffs: a systematic review of the literature. Acad Med 2009, 84:1775-1787.
14. Garland A, Shaman Z, Baron J, Connors AF Jr: Physician-attributable differences in intensive care unit costs: a single-center study. Am J Respir Crit Care Med 2006, 174:1206-1210.

15. Kress JP, Pohlman AS, O'Connor MF, Hall JB: Daily interruption of sedative infusions in critically ill patients undergoing mechanical ventilation. N Engl J Med 2000, 342:1471-1477.

16. Ely EW, Baker AM, Dunagan DP, Burke HL, Smith AC, Kelly PT, Johnson MM, Browder RW, Bowton DL, Haponik EF: Effect on the duration of mechanical ventilation of identifying patients capable of breathing spontaneously. NEngl J Med 1996, 335:1864-1869.

17. Blackwood B, Alderdice F, Burns $K$, Cardwell C, Lavery G, O'Halloran P: Use of weaning protocols for reducing duration of mechanical ventilation in critically ill adult patients: Cochrane systematic review and meta-analysis. BMJ 2011, 342:C7237.

18. Tissue plasminogen activator for acute ischemic stroke. The National Institute of Neurological Disorders and Stroke rt-PA Stroke Study Group. NEngl J Med 1995, 333:1581-1587.

19. Mild therapeutic hypothermia to improve the neurologic outcome after cardiac arrest. N Engl J Med 2002, 346:549-556.

20. Bernard SA, Gray TW, Buist MD, Jones BM, Silvester W, Gutteridge G, Smith K: Treatment of comatose survivors of out-of-hospital cardiac arrest with induced hypothermia. N Engl J Med 2002, 346:557-563.

21. Dellinger RP, Levy MM, Carlet JM, Bion J, Parker MM, Jaeschke R, Reinhart K, Angus DC, Brun-Buisson C, Beale R, Calandra T, Dhainaut JF, Gerlach H, Harvey M, Marini JJ, Marshall J, Ranieri M, Ramsay G, Sevransky J, Thompson BT, Townsend S, Vender JS, Zimmerman JL, Vincent JL; International Surviving Sepsis Campaign Guidelines Committee; American Association of CriticalCare Nurses; American College of Chest Physicians; American College of Emergency Physicians; Canadian Critical Care Society; European Society of Clinical Microbiology and Infectious Diseases; et al:: Surviving Sepsis Campaign: international guidelines for management of severe sepsis and septic shock: 2008. Crit Care Med 2008, 36:296-327.

22. Girard TD, Kress JP, Fuchs BD, Thomason JW, Schweickert WD, Pun BT, Taichman DB, Dunn JG, Pohlman AS, Kinniry PA, Jackson JC, Canonico AE, Light RW, Shintani AK, Thompson JL, Gordon SM, Hall JB, Dittus RS, Bernard GR, Ely EW: Efficacy and safety of a paired sedation and ventilator weaning protocol for mechanically ventilated patients in intensive care (Awakening and Breathing Controlled trial): a randomised controlled trial. Lancet 2008, 371:126-134.

23. Hebert PC, Wells G, Blajchman MA, Marshall J, Martin C, Pagliarello G, Tweeddale M, Schweitzer I, Yetisir E: A multicenter, randomized, controlled clinical trial of transfusion requirements in critical care. Transfusion Requirements in Critical Care Investigators, Canadian Critical Care Trials Group. N Engl J Med 1999, 340:409-417.

24. Rivers E, Nguyen B, Havstad S, Ressler J, Muzzin A, Knoblich B, Peterson E, Tomlanovich M: Early goal-directed therapy in the treatment of severe sepsis and septic shock. N Engl J Med 2001, 345:1368-1377.

25. FDA Drug Safety Communication: Voluntary market withdrawal of Xigris [drotrecogin alfa (activated)] due to failure to show a survival benefit: Safety Anouncement 2011 [http://www.fda.gov/Drugs/DrugSafety/ ucm277114.htm]

26. Annane D, Sébille V, Charpentier C, Bollaert PE, François B, Korach JM, Capellier G, Cohen Y, Azoulay E, Troché G, Chaumet-Riffaud P, Bellissant E: Effect of treatment with low doses of hydrocortisone and fludrocortisone on mortality in patients with septic shock. JAMA 2002, 288:862-871.

27. Bernard GR, Vincent JL, Laterre PF, LaRosa SP, Dhainaut JF, Lopez-Rodriguez A, Steingrub JS, Garber GE, Helterbrand JD, Ely EW, Fisher CJ Jr; Recombinant human protein C Worldwide Evaluation in Severe Sepsis (PROWESS) study group: Efficacy and safety of recombinant human activated protein $\mathrm{C}$ for severe sepsis. NEngl J Med 2001, 344:699-709.

28. Brunkhorst FM, Engel C, Bloos F, Meier-Hellmann A, Ragaller M, Weiler N, Moerer O, Gruendling M, Oppert M, Grond S, Olthoff D, Jaschinski U, John S, Rossaint R, Welte T, Schaefer M, Kern P, Kuhnt E, Kiehntopf M, Hartog C, Natanson C, Loeffler M, Reinhart K; German Competence Network Sepsis (SepNet): Intensive insulin therapy and pentastarch resuscitation in severe sepsis. N Engl J Med 2008, 358:125-139.

29. NICE-SUGAR Study Investigators, Finfer $S$, Chittock DR, Su SY, Blair D, Foster D, Dhingra V, Bellomo R, Cook D, Dodek P, Henderson WR, Hébert PC, Heritier S, Heyland DK, McArthur C, McDonald E, Mitchell I, Myburgh JA, Norton R, Potter J, Robinson BG, Ronco JJ: Intensive versus conventional glucose control in critically ill patients. N Engl J Med 2009, 360:1 283-1297. 
30. Sprung CL, Annane D, Keh D, Moreno R, Singer M, Freivogel K, Weiss YG, Benbenishty J, Kalenka A, Forst H, Laterre PF, Reinhart K, Cuthbertson BH, Payen D, Briegel J; CORTICUS Study Group: Hydrocortisone therapy for patients with septic shock. N Engl J Med 2008, 358:111-124.

31. van den Berghe $G$, Wouters $P$, Weekers F, Verwaest C, Bruyninckx F, Schetz M Vlasselaers D, Ferdinande P, Lauwers P, Bouillon R: Intensive insulin therapy in the critically ill patients. N Engl J Med 2001, 345:1359-1367.

32. Sinuff T, Patel RV, Adhikari NK, Meade MO, Schunemann HJ, Cook DJ: Quality of professional society guidelines and consensus conference statements in critical care. Crit Care Med 2008, 36:1049-1058.

33. Schmidt GA: Roger C. Bone Memorial Lecture, Protocols vs Physiology: Which Should Guide Intensive Care? In Chest 2011; October 22-26, 2011; Honolulu, Hawaii.

34. Mercat A, Richard JC, Vielle B, Jaber S, Osman D, Diehl JL, Lefrant JY, Prat G, Richecoeur J, Nieszkowska A, Gervais C, Baudot J, Bouadma L, Brochard L; Expiratory Pressure (Express) Study Group: Positive end-expiratory pressure setting in adults with acute lung injury and acute respiratory distress syndrome: a randomized controlled trial. JAMA 2008, 299:646-655.

35. Jain R, Chung SM, Jain L, Khurana M, Lau SW, Lee JE, Vaidyanathan J, Zadezensky I, Choe S, Sahajwalla CG: Implications of obesity for drug therapy: limitations and challenges. Clin Pharmacol Ther 2011, 90:77-89.

36. Casey CM, Balas MC: Use of protocols in older intensive care unit patients: is standardization appropriate? AACN Adv Crit Care 2011, 22:150-160.
37. Lellouche F, Mancebo J, Jolliet P, Roeseler J, Schortgen F, Dojat M, Cabello B, Bouadma L, Rodriquez P, Maggiore S, Reynaert M, Mersmann S, Brochard L: A multicenter randomized trial of computer-driven protocolized weaning from mechanical ventilation. Am J Respir Crit Care Med 2006, 174:894-900.

38. Rose L, Presneill JJ, Johnston L, Cade JF: A randomised, controlled trial of conventional versus automated weaning from mechanical ventilation using SmartCare/PS. Intensive Care Med 2008, 34:1788-1795.

39. Ali NA, Gutteridge D, Shahul S, Checkley W, Sevransky J, Martin GS: Critical illness outcome study: an observational study of protocols and mortality in intensive care units. Open Access J Clin Trials 2011, 3:55-65.

40. Weiss CH, Moazed F, McEvoy CA, Singer BD, Szleifer I, Amaral LA, Kwasny M, Watts CM, Persell SD, Baker DW, Sznajder JI, Wunderink RG: Prompting physicians to address a daily checklist and process of care and clinical outcomes: a single-site study. Am J Respir Crit Care Med 2011, 184:680-686.

41. Morris AH, Hirshberg E, Sward KA: Computer protocols: how to implement. Best Practice Res Clin Anaesthesiol 2009, 23:51-67.

doi:10.1186/cc10578

Cite this article as: Chang SY, et al:: Protocols in the management of critical illness. Critical Care 2012, 16:306. 